\title{
EVALUASI GEDUNG ARSIP POLITEKNIK NEGERI JAKARTA SESUAI SNI 1726-2019 DAN SNI 2847-2019
}

\author{
Yanuar Setiawan', Bima Ryanto ${ }^{2}$, Mikha Geraldine ${ }^{3}$, Rinawati $^{4}$ \\ 1,2,3,4 Jurusan Teknik Sipil, Politeknik Negeri Jakarta, Jalan Prof. Dr. G. A. Siwabessy, Kampus Baru UI, \\ Kukusan, Kecamatan Beji, Kota Depok, Jawa Barat, 16424 \\ e-mail : yanuar.setiawan@sipil.pnj.ac.id
}

\begin{abstract}
The purpose of this research is to recalculate the upper structure of the X building of Jakarta State Polytechnic uses SNI-2847-2019 regulations regarding concrete and SNI 1726- 2019regarding earthquakes. This building consists of 3 floors which use concrete as its main structure. Recalculation includes structural elements starting from collar beam, floor plates, beams, and columns, which are expected to withstand the loads who worked on it. Structural analysis was performed using the ETABS 2013 software. Especially for the calculation of the column structure, the SP Column software is used. The results were obtained from the recalculation of the PNJ $x$ Building in the form of dimensional differences and reinforcement against the existing building. Dimension and reinforcement after redesign became more the size of the existing building. The recalculation results indicate that planning re-using SNI 1726-2019 and SNI 2847-2019 are strong to bear the working load after the dimensions and reinforcement are enlarged.
\end{abstract}

Keywords : Structure, concrete, dimensions

\begin{abstract}
ABSTRAK
Tujuan dari penelitian ini adalah untuk menghitung ulang struktur atas Gedung Arsip Politeknik Negeri Jakarta menggunakan peraturan SNI-2847-2019 tentang beton dan SNI1726-2019 tentang gempa. Bangunan ini terdiri dari 3 lantai yang menggunakan beton sebagai struktur utamanya. Perhitungan ulang meliputi elemen - elemen struktur mulai dari gording, kuda - kuda, pelat lantai, balok, dan kolom yang diharapkan dapat menahan beban-beban yang bekerja diatasnya. Analisa struktur dilakukan menggunakan software ETABS 2013. Khusus untuk perhitungan kolom struktur digunakan software SP Column. Hasil yang didapat dari perhitungan ulang Gedung Arsip PNJ ini berupa perbedaan dimensi dan penulangan terhadap bangunan eksisting. Dimensi dan penulangan setelah di desain ulang menjadi lebih besar dari bangunan eksisting. Hasil perhitungan ulang menunjukkan bahwa perencanaan ulang menggunakan SNI-1726-2019 dan SNI-2847-2019 kuat memikul beban yang bekerja setelah dimensi dan penulangan tersebut diperbesar.
\end{abstract}

Kata kunci : Struktur, beton, dimensi

\section{PENDAHULUAN}

Menurut Undang - Undang Nomor 28 Tahun 2002 tentang bangunan gedung, bangunan gedung merupakan hal yang penting dalam menunjang kebutuhan dasar manusia [1]. Perkembangan dan kemajuan teknologi di Indonesia menyebabkan kebutuhan akan konstruksi suatu bangunan gedung terus meningkat [2]. Seiring berjalannya waktu, peraturan untuk mendesain suatu konstruksi juga terus diperbaharui. Diperlukan perhitungan perencanaan yang cermat dan tepat agar konstruksi suatu bangunan kokoh dan ekonomis [3].

Pada tahun 2019, telah diterbitkan SNI 1726 - 2019 tentang Tata Cara Perencanaan Ketahanan Gempa untuk Struktur Bangunan Gedung dan Nongedung [4] serta SNI 2847 - 2019 tentang Persyaratan Beton Struktural untuk Bangunan Gedung [5]. Tentunya diterbitkannya peraturan baru tersebut ada keterkaitannya dengan perubahan 
persyaratan dimensi maupun penulangan dari komponen struktur dari sebuah bangunan gedung. Karena peraturan tersebut mengatur tentang penulangan pada beton dan juga mengatur tentang beban gempa pada suatu struktur bangunan gedung. Pada peraturan tersebut terdapat ketentuan - ketentuan yang berbeda dari SNI 1726 - 2002 misalnya seperti peta gempa Indonesia yang tentunya akan mempengaruhi desain respon spektrumnya.

Penyusunan penelitian ini mengevaluasi struktur atas Gedung Arsip Politeknik Negeri Jakarta yang dibangun pada tahun 2008. Dimana gedung ini di desain menggunakan SNI 03 - 2847 - 2002 tentang Tata Cara Perhitungan Struktur Beton untuk Bangunan Gedung [6] dan SNI 03 - 1726 - 2002 tentang Standar Perencanaan Ketahanan Gempa Struktur Bangunan Gedung [7]. Pada saat ini, peraturan beton telah diperbaharui menjadi SNI 2847 - 2019 dan peraturan gempa SNI 1726 - 2019. Adanya pembaruan pada peraturan yang ada, akan mempengaruhi detailing elemen struktur atas Gedung Arsip Politeknik Negeri Jakarta.

Berdasarkan latar belakang tersebut di atas maka permasalahan yang diangkat dalam penelitian ini adalah bagaimana hasil akhir evaluasi struktur atas Gedung Arsip Politeknik Negeri Jakarta sesuai dengan SNI 2847 - 2019 dan SNI 1726 2019.

Adapun tujuan dari penelitian ini adalah untuk mengevaluasi struktur atas Gedung Arsip Politeknik Negeri Jakarta sesuai dengan SNI 2847 - 2019 dan SNI 1726 - 2019 dan untuk mengetahui elemen - elemen struktur masih memenuhi syarat kelayanan atau tidak.

Batasan-batasan dalam penelitian ini adalah analisis pembebanan dan gaya dalam dilakukan dengan menggunakan program Software Structure Analisis ETABS 2013 dan SP Column, evaluasi struktur atas mengacu pada SNI 2847 2019, perhitungan beban gempa mengacu pada SNI 1726 - 2019, data yang didapat berupa denah struktur, dimensi struktur kolom, balok, plat, tangga serta gambar potongan.

\section{METODE PENELITIAN}

Penelitian ini meliputi perhitungan gempa, penutup atap, pelat lantai, balok dan kolom dengan mengevaluasi sesuai dengan peraturan SNI 2847 - 2019 dan SNI 1726 - 2019. Adapun material dan dimensi struktur didapatkan dari as built drawing Gedung Arsip PNJ. Berikut ini adalah tahapan prosesnya:

\section{Studi Lapangan}

Mendapatkan as built drawing Gedung Arsip dan mempelajari bentuk struktur atas dari gedung tersebut. Mempelajari bentuk ruang dan dimensi yang digunakan.

\section{Pengumpulan Data}

Pada penelitian ini untuk perhitungan gempa menggunakan data hasil pengujian pada laboratorium tanah. Untuk mutu beton dan dimensi menggunakan data yang didapat dari as built drawing. Mutu beton yang digunakan adalah beton dengan kuat tekan (fc') $36 \mathrm{MPa}$. Mutu baja tulangan yang digunakan adalah BJTD 24 untuk tulangan polos dan BJTD 40 untuk tulangan ulir. Sedangkan mutu baja profil yang digunakan pada struktur rangka atap adalah BJ 37.

\section{Analisa Struktur}

Mendesain bentuk bangunan gedung dengan menggunakan software ETABS 2013 beserta kombinasi pembebanannya sesuai dengan SNI 1726 - 2019 dengan menginput beban- beban yang bekerja sesuai standar beban pada SNI 1727 2013 tentang Beban Minimum untuk 
Perancangan Bangunan Gedung dan Struktur Lain [8] pada struktur gedung Arsip. Gambar 1 memperlihatkan model dari struktur.

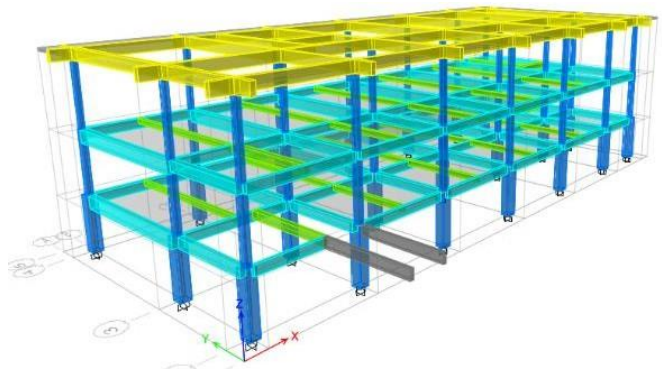

Gambar 1 Permodelan Struktur pada Program ETABS 2013

\section{Menentukan Gaya-gaya Dalam dan Desain Elemen Struktur}

Menentukan berat bangunan, gaya gempa, gaya dalam maksimum pada elemen struktur yang meliputi momen, gaya geser, dan gaya aksial pada balok dan kolom dari hasil permodelan yang telah dirunning hasilnya. Dari hasil running program ETABS 2013 dapat juga menentukan desain elemen struktur dengan mengacu kepada luas penampang hasil permodelan struktur.

\section{HASIL dan PEMBAHASAN}

\section{Berat Bangunan Tiap Lantai}

Hasil running ETABS 2013 untuk perhitungan berat bangunan dapat dilihat pada Tabel 1.

Tabel 1. Berat Bangunan Tiap Lantai

\begin{tabular}{ccc}
\hline Lantai & $\begin{array}{c}\text { Beban Mati } \\
(\text { KN) }\end{array}$ & $\begin{array}{c}\text { Beban Hidup } \\
(\text { KN) }\end{array}$ \\
\hline 3 & 1903,2298 & 306,905 \\
\hline 2 & 4955,6994 & 2032,76 \\
\hline 1 & 4948,4289 & 1964,51 \\
\hline
\end{tabular}

\section{Perhitungan Beban Gempa}

Pada perhitungan beban gempa, lokasi gedung arsip berada di daerah Depok, Jawa Barat dimana kategori resiko bangunan gedung fasilitas pendidikan adalah IV dengan faktor keutamaan gempa 1,50. Beban gempa dihitung dengan menggunakan metode statik ekivalen. Didapat hasil beban gempa tiap lantai seperti Tabel 2.

Tabel 2. Beban Gempa Gedung Arsip

\begin{tabular}{ccccc}
\hline Lantai & $\begin{array}{c}\text { Fx } \\
\text { (kgf) }\end{array}$ & $\begin{array}{c}\text { 30\% } \\
\text { Fx } \\
\text { (kgf) }\end{array}$ & $\begin{array}{c}\text { Fy } \\
\text { (kgf) }\end{array}$ & $\begin{array}{c}\text { 30\% } \\
\text { Fy } \\
\text { (kgf) }\end{array}$ \\
\hline 3 & 947,36 & 284,21 & 947,36 & 284,21 \\
\hline 2 & 910,03 & 273,01 & 910,03 & 273,01 \\
\hline 1 & 499,19 & 149,76 & 499,19 & 149,76 \\
\hline
\end{tabular}

\section{Rekapitulasi Gaya Dalam dan Penulangan pada Balok}

Setelah running permodelan struktur oleh program ETABS 2013, hasil gaya dalam yang timbul dapat dilihat pada Tabel 3. Hasil perbandingan dimensi eksisting dan kebutuhan dimensi dari hasil desain dapat dilihat pada Tabel 4 . Hasil perbandingan tulangan eksisting dan hasil desain tulangan pada elemen balok dapat dilihat pada Tabel 7-8.

Tabel 3. Rekapitulasi Gaya Dalam pada Balok

\begin{tabular}{ccccc}
\hline \multirow{2}{*}{ Section } & \multicolumn{2}{c}{ Tumpuan } & \multicolumn{2}{c}{ Lapangan } \\
\cline { 2 - 5 } & $\mathrm{Vu}$ & $\mathrm{Mu}$ & $\mathrm{Vu}$ & $\mathrm{Mu}$ \\
\hline B3 & 216.14 & 436.76 & 67.94 & 200.04 \\
\hline B4 & 189.91 & 288.63 & 133.08 & 171.66 \\
\hline B5 & 34.45 & 45,10 & 10,76 & 16,22 \\
\hline B6 & 239.17 & 310.38 & 154.12 & 245.93 \\
\hline B7 & 65.71 & 64.17 & 10.14 & 78.67 \\
\hline B8 & 173.32 & 242.96 & 40.50 & 180.40 \\
\hline B9 & 81.21 & 132.64 & 17.30 & 115.41 \\
\hline
\end{tabular}

Tabel 4. Perbandingan Dimensi

Eksisting dan Kebutuhan Dimensi Baru pada Balok

\begin{tabular}{ccccc}
\hline No & $\begin{array}{c}\text { Tipe } \\
\text { Balok }\end{array}$ & $\begin{array}{c}\text { Panjang } \\
(\mathbf{m m})\end{array}$ & $\begin{array}{c}\text { Dimensi } \\
\text { Eksisting } \\
\left(\mathbf{m m}^{2}\right)\end{array}$ & $\begin{array}{c}\text { Kebutuhan } \\
\text { Dimensi } \\
\left(\mathbf{m m}^{\mathbf{2}}\right)\end{array}$ \\
\hline 1 & B3 & 8320 & $300 \times 700$ & $300 \times 700$ \\
\hline 2 & B4 & 6000 & $300 \times 500$ & $300 \times 500$ \\
\hline 3 & B5 & 5000 & $300 \times 400$ & $300 \times 400$ \\
\hline 4 & B6 & 6000 & $200 \times 500$ & $300 \times 500$ \\
\hline 5 & B7 & 8320 & $200 \times 400$ & $400 \times 500$ \\
\hline 6 & B8 & 8320 & $200 \times 300$ & $450 \times 500$ \\
\hline 7 & B9 & 8320 & $250 \times 600$ & $300 \times 600$ \\
\hline
\end{tabular}




\section{Analisis}

Berdasarkan tabel - tabel perbandingan kondisi eksisting dan kebutuhan hasil desain didapatkan hasil akhir evaluasi pada elemen balok B3, B4 memenuhi syarat dimensi tetapi penulangannya tidak terpenuhi. Untuk Balok B5 baik dimensi maupun penulangan memenuhi syarat dan aman digunakan. Untuk Balok B6, B7, B8, dan B9, baik dimensi maupun penulangannya tidak memenuhi syarat.

\section{Rekapitulasi Gaya Dalam dan Penulangan pada Kolom}

Setelah running permodelan struktur oleh program ETABS 2013, hasil gaya dalam yang timbul dapat dilihat pada Tabel 5. Hasil perbandingan dimensi eksisting dan kebutuhandimensi desain dapat dilihat pada Tabel 6. Hasil desain tulangan pada elemen struktur kolom dapat dilihat pada Tabel 9.

Tabel 5. Rekapitulasi Gaya Dalam pada Kolom

\begin{tabular}{ccc}
\hline $\begin{array}{c}\text { Tipe } \\
\text { Kolom }\end{array}$ & Pu (kN) & $\begin{array}{c}\text { Mu } \\
(\mathbf{k N m})\end{array}$ \\
\hline K1 & 1881,62 & 531,77 \\
\hline K2 & 960,95 & 267,23 \\
\hline K3 & 76,32 & 128,38 \\
\hline
\end{tabular}

Tabel 6. Perbandingan Dimensi

Eksisting dan Kebutuhan Dimensi Baru pada Kolom

\begin{tabular}{ccccc}
\hline No & $\begin{array}{c}\text { Tipe } \\
\text { Kolom }\end{array}$ & $\begin{array}{c}\text { Panjang } \\
(\mathbf{m m})\end{array}$ & $\begin{array}{c}\text { Dimensi } \\
\text { Eksisting } \\
(\mathbf{m m 2})\end{array}$ & $\begin{array}{c}\text { Kebutuhan } \\
\text { Dimensi } \\
(\mathbf{m m 2})\end{array}$ \\
\hline 1 & K1 & 3060 & $550 \times 550$ & $550 \times 550$ \\
\hline 2 & K2 & 3420 & $300 \times 300$ & $500 \times 500$ \\
\hline 3 & K3 & 4020 & $250 \times 250$ & $400 \times 400$ \\
\hline
\end{tabular}

Analisis

Berdasarkan tabel - tabel perbandingan kondisi eksisting dan kebutuhan hasil desain didapatkan bahwa hasil akhir evaluasi pada elemen kolom K1 memenuhi syarat tetapi pada tulangan geser tidak memenuhi syarat. Sedangkan pada elemen kolom K2 dan K3 dimensi dan penulangannya tidak memenuhi syarat baik tulangan utama maupun tulangan gesernya.

\section{KESIMPULAN}

Berdasarkan pembahasan terhadap evaluasi struktur atas pada Gedung Arsip PNJ dapat disimpulkan bahwa hasil evaluasi pada elemen balok B3, B4 memenuhi syarat dimensi tetapi penulangannya tidak terpenuhi. Untuk Balok B5 baik dimensi maupun penulangan memenuhi syarat dan aman digunakan. Untuk Balok B6, B7, B8, dan B9 baik dimensi maupun penulangannya tidak memenuhi syarat. Hasil evaluasi menunjukkan bahwa elemen kolom lantai 1 dimensi dan penulangan memenuhi syarat, tetapi pada tulangan geser tidak memenuhi syarat. Pada elemen kolom lantai 2 dan 3 dimensi dan penulangannya tidak memenuhi syarat baik tulangan utama maupun tulangan geser.

\section{DAFTAR PUSTAKA}

[1] S. N. R. Indonesia, Undang Undang Nomor 28 Tahun 2002 Tentang Bangunan Gedung, Jakarta: Direktorat Jendral Perumahan dan Permukiman, Departement Permukiman dan Prasarana WIlayah, 2002.

[2] C. A. Pribudi, "Analisis Strategi Operasional Tower Apartemen," Architecture Innovation, vol. 2, no. 2, p. 22, 2018.

[3] G. H. Cahyo, "Perhitungan Perencanaan Struktur Gedung Beton Bertulang di Jalan Ahmad Yani Pontianak," Teknik SIpil UNTAN, vol. 10, no. 2, 2010.

[4] B. S. N. Indonesia, SNI 1726 - 2019 Tentang Tata Cara Perencanaan Ketahanan Gempa untuk Struktur Bangunan Gedung dan Non gedung, 
Jakarta: Badan Standar Nasional Indonesia, 2019.

[5] B. S. N. Indonesia, SNI 2847 - 2019 Tentang Persyaratan Beton Struktural untuk Bangunan Gedung, Jakarta: Badan Standar Nasional Indonesia, 2019.

[6] B. S. N. Indonesia, SNI 03 - 2847 2002 Tentang Tata Cara Perhitungan Struktur Beton untuk Bangunan Gedung, Jakarta : Badan Standar Nasional Indonesia, 2002.
[7] B. S. N. Indonesia, SNI 03 - 1726 2002 Tentang Standar Perencanaan Ketahanan Gempa Struktur Bangunan Gedung, Jakarta: Badan Standar Nasional Indonesia, 2002.

[8] B. S. N. Indonesia, SNI 1727 - 2013 Tentang Beban Minimum untuk Perancangan Bangunan Gedung dan Struktur Lain, Jakarta: Badan Standar Nasional Indonesia, 2013.

Tabel 7. Perbandingan Tulangan Utama Eksisting dan Kebutuhan Tulangan Utama Baru pada Balok

\begin{tabular}{|c|c|c|c|c|c|c|c|c|c|}
\hline \multirow{3}{*}{ No } & \multirow{3}{*}{$\begin{array}{c}\text { Tipe } \\
\text { Balok }\end{array}$} & \multicolumn{4}{|c|}{ Tulangan Utama Eksisting } & \multicolumn{4}{|c|}{ Kebutuhan Tulangan Utama } \\
\hline & & \multicolumn{2}{|c|}{ Tumpuan } & \multicolumn{2}{|c|}{ Lapangan } & \multicolumn{2}{|c|}{ Tumpuan } & \multicolumn{2}{|c|}{ Lapangan } \\
\hline & & Atas & Bawah & Atas & Bawah & Atas & Bawah & Atas & Bawah \\
\hline 1 & B3 & 8D16 & 4D16 & 4D16 & 10D16 & 8D19 & 4D19 & 2D19 & 4D19 \\
\hline 2 & B4 & 5D16 & 3D16 & $2 \mathrm{D} 16$ & $5 \mathrm{D} 16$ & 8D19 & 5D19 & 3D19 & $5 \mathrm{D} 19$ \\
\hline 3 & B5 & 4D13 & 3D13 & 3D13 & 4D13 & 4D13 & 3D13 & 3D13 & 4D13 \\
\hline 4 & B6 & $6 \mathrm{D} 16$ & $3 \mathrm{D} 16$ & $3 \mathrm{D} 16$ & $6 \mathrm{D} 16$ & 10D19 & 7D19 & 4D19 & $8 \mathrm{D} 19$ \\
\hline 5 & B7 & 3D13 & 2D13 & $2 \mathrm{D} 13$ & 3D13 & 3D16 & 2D16 & 2D16 & $4 \mathrm{D} 16$ \\
\hline 6 & B8 & 5D13 & 3D13 & 2D13 & 3D13 & 10D19 & 5D19 & 3D19 & 6D19 \\
\hline 7 & B9 & 3D13 & 2D13 & 2D13 & 3D13 & 3D19 & 2D19 & 2D19 & 3D19 \\
\hline
\end{tabular}

Tabel 8. Perbandingan Tulangan Geser Eksisting dan Kebutuhan Tulangan Baru pada Balok

\begin{tabular}{|c|c|c|c|c|c|}
\hline \multirow{2}{*}{ No } & \multirow{2}{*}{$\begin{array}{c}\text { Tipe } \\
\text { Balok }\end{array}$} & \multicolumn{2}{|c|}{$\begin{array}{c}\text { Tulangan Geser } \\
\text { Eksisting }\end{array}$} & \multicolumn{2}{|c|}{$\begin{array}{c}\text { Kebutuhan Tulangan } \\
\text { Geser }\end{array}$} \\
\hline & & Tumpuan & Lapangan & Tumpuan & Lapangan \\
\hline 1 & B3 & $\varnothing 10-100$ & $\varnothing 10-200$ & 3D13 - 100 & D13 - 150 \\
\hline 2 & B4 & $\varnothing 10-100$ & $\varnothing 10-200$ & 4D13 - 100 & $3 \mathrm{D} 13-200$ \\
\hline 3 & B5 & $\varnothing 10-100$ & $\varnothing 10-200$ & D10 - 80 & D10 - 150 \\
\hline 4 & B6 & $\varnothing 10-100$ & $\varnothing 10-200$ & $5 \mathrm{D} 13-100$ & 4D13 - 200 \\
\hline 5 & B7 & $\varnothing 10-100$ & $\varnothing 10-200$ & D10 - 100 & D10 - 200 \\
\hline 6 & B8 & $\varnothing 10-100$ & $\varnothing 10-200$ & $6 \mathrm{D} 13-100$ & D13 - 200 \\
\hline 7 & B9 & $\varnothing 10-100$ & $\varnothing 10-200$ & D10 - 100 & D10 - 200 \\
\hline
\end{tabular}


Yanuar, dkk., Evaluasi Gedung Arsip...

Tabel 9. Perbandingan Tulangan Eksisting dan Kebutuhan Tulangan Baru pada Kolom

\begin{tabular}{|c|c|c|c|c|c|c|c|}
\hline \multirow{2}{*}{ No } & \multirow{2}{*}{$\begin{array}{l}\text { Tipe } \\
\text { Kolom }\end{array}$} & \multirow{2}{*}{$\begin{array}{c}\text { Tulangan } \\
\text { Utama } \\
\text { Eksisting }\end{array}$} & \multirow{2}{*}{$\begin{array}{c}\text { Kebutuhan } \\
\text { Tulangan } \\
\text { Utama }\end{array}$} & \multicolumn{2}{|c|}{ Tulangan Geser Eksisting } & \multicolumn{2}{|c|}{$\begin{array}{c}\text { Kebutuhan Tulangan } \\
\text { Geser }\end{array}$} \\
\hline & & & & Tumpuan & Lapangan & Tumpuan & Lapangan \\
\hline 1 & K1 & $16 \mathrm{D} 22$ & 16 D22 & $\varnothing 8-125$ & $\varnothing 8-125$ & 5D13-100 & D13 - 100 \\
\hline 2 & K2 & 12 D16 & 16 D19 & $\varnothing 8-125$ & $\varnothing 8-125$ & $5 \mathrm{D} 13-100$ & D13 - 100 \\
\hline 3 & K3 & $6 \mathrm{D} 16$ & 14 D16 & $\varnothing 8-125$ & $\varnothing 8-125$ & $4 \mathrm{D} 13-90$ & D13 - 90 \\
\hline
\end{tabular}

